\title{
Keanekaragaman Serangga pada Pertanaman Jagung di Lahan Tadah Hujan Kabupaten Pati-Jawa Tengah
}

\author{
Asep Kurnia*, E. Srihayu Harsanti, Mas Teddy Sutraidi, Sri Hartini \\ Balai Penelitian Lingkungan Pertanian \\ *Alamat korespondensi: asep_balingtan@yahoo.co.id
}

\begin{abstract}
Diversity of insects on maize cropping in rainfed land at Pati Regency, Central Java

Insects diversities are influenced by many factors such as food availability, space and interactions between individuals. The purpose of this study was to understand the diversity of insect populations in maize cropping on rainfed agricultural land. This experiment used survey method to collect data and then find the diversity index value. Insect collection was completed using light trap, pitfall, and swing net, in which observation using each tool were repeated 3,2 , and 5 times in a week, respectively. The experiment was carried out at rainfed land of Jakenan field station using area $5000 \mathrm{~m}^{2}$ with altitude 7 $\mathrm{m}$ above sea level (masl). The most dominant insect population on light trap observation was order of Lepidoptera in the form of moths, while the observations using fit-fall was dominated by insect from the Hymenoptera order in the form of ants and bees. Furthermore, observation using insect swing net was the Hemiptera order or the ladybug group as the most dominant. However, in general order of Hemiptera was the most dominant when all of the insect collected from those three collections method added. Diversity index was categorized medium as it was the value range of $1<\mathrm{H}^{`}<3$
\end{abstract}

\begin{abstract}
ABSTRAK
Keanekaragaman serangga dipengaruhi oleh banyak faktor misalnya ketersediaan makanan, ruang dan interaksi antar individu. Penelitian ini bertujuan untuk mengetahui keanekaragaman serangga pada pertanaman jagung di lahan tadah hujan. Penelitian ini menggunakan metode survey, dimana data yang dikumpulkan meliputi jumlah dan jenis serangga yang tertangkap yang kemudian dihitung indeks keragamannya. Pengumpulan serangga dilakukan dengan menggunakan perangkap cahaya (light trap), perangkap jebakan (pitfall) dan jala ayun (swing net) dimana setiap minggunya pada perangkap lampu dilakukan 3 kali pengamatan, perangkap jebakan dilakukan 2 kali dan jala ayun dilakukan 5 kali. Percobaan dilakukan di lahan tadah hujan kebun percobaan Jakenan dengan luas lahan berukuran 5000 $\mathrm{m}^{2}$ pada ketinggian 7 meter di atas permukaan laut (mdpl). Jenis serangga yang dominan pada pengamatan perangkap lampu adalah serangga dari ordo Lepidoptera yaitu berupa ngengat, sedangkan pada pengamatan menggunakan perangkap jebakan yang dominan adalah serangga dari golongan Hymenoptera atau berupa semut dan lebah. Sementara itu pada pengamatan menggunakan jala ayun serangga yang dominan adalah dari ordo Hemiptera atau golongan kepik. Akan tetapi secara umum dari ketiga metode penangkapan tersebut, ordo serangga yang mendominasi pertanaman jagung tadah hujan adalah ordo Hemiptera. Indeks keragaman serangga pada pertanaman tersebut berada pada kisaran $1<\mathrm{H}^{`}<3$ yang berarti kategori sedang.

Kata kunci: Keragaman, Serangga, Jagung, Lahan, Tadah hujan.
\end{abstract}

\section{PENDAHULUAN}

Indonesia dikenal sebagai salah satu negara yang memiliki kekayaan jenis flora dan fauna yang sangat tinggi (Shahabuddin dkk., 2005). Setiap ekosistem peranian memiliki keanekaragaman serangga yang khas yang disebabkan keseragaman jenis tanaman sehingga hanya serangga yang memiliki preferensi terhadap tanaman tersebut yang banyak ditemukan (Khaliqet al., 2014, Taradipha dkk., 
2018). Selain itu, iklim atau cuaca juga menentukan terhadap keberadaan serangga di ekosistem tersebut, sehingga di ekosistem pertanian tertentu jenis dan jumlah serangganya pun berbeda dengan ekosistem pertanian lain (Mas'ud dkk., 2009).

Lahan tadah hujan merupakan ekosistem pertanian yang memiliki karakter tersendiri dimana pengairan untuk tanaman hanya mengandalkan air hujan tanpa adanya sumber air tanah maupun air irigasi, Pola tanam pada lahan tadah hujan mengikuti pola dan curah hujan yang ada. Di Indonesia pola tanam di lahan tadah hujan biasanya dimulai pada akhir tahun dimana musim hujan mulai muncul yang kemudian dikategorikan sebagai musim tanam ke I, kemudian berlanjut ke musim tanam ke II yang berlangsung pada awal tahun karena kemungkinan masih ada air. Pada musim tanam ke III biasanya petani ada yang tanam ada pula yang tidak, tergantung pada ketersediaan air. Untuk petani yang memiliki cadangan air baik dalam embung atau tandon air biasanya masih melakukan penanaman dengan komoditas yang membutuhkan air yang sedikit. Pola iklim dan pola tanam seperti ini membawa pengaruh terhadap keragaman dan dinamika populasi serangga yang ada (Yamamuraet al, 2006., Ashfaqetal., 2011). Pada kondisi seperti ini maka pengelolaan serangga hama oleh petani juga akan menghasilkan cara yang berbeda (Susanto dkk., 2018), sehingga penanganannya akan lebih tepat, efektif dan efisien. Lahan tadah hujan di Indonesia mencapai sekitar 2 juta hektar sedangkan di dunia mencapai 15 juta hektar. Ekosistem pertanian jagung $60 \%$ berada di lahan kering, $20 \%$ di lahan tadah hujan, dan $20 \%$ di lahan sawah irigasi (Kasryno dkk., 2002)

Jagung (Zea mays L.) merupakan salah satu tanaman palawija yang menjadi primadona dalam agribisnis, baik di Indonesia maupun dunia. Jagung juga merupakan salah satu tanaman pangan utama selain padi dan kedelai. Jagung secara spesifik merupakan tanaman pangan yang sangat bermanfaat bagi kehidupan manusia ataupun hewan. Jagung termasuk komoditas strategis dalam pembangunan pertanian dan perekonomian Indonesia, karena komoditas ini mempunyai fungsi multiguna, baik untuk pangan maupun pakan. Jagung juga digunakan sebagai makanan hewan ternak dan digiling menjadi tepung jagung untuk produk-produk makanan, minuman, pelapis kertas, dan fermentasi (Oktavia, 2017)

Salelau \& Maryam (2018) melaporkan bahwa salah satu kendala yang sering dihadapi dalam peningkatan produksi jagung adalah abiotik dan biotik. Kendala abiotik disebabkan oleh rendahnya ketersediaan hara di tanah, sementara kendala biotik meliputi gangguan yang disebabkan oleh organisme pengganggu tanaman (OPT) yang salah satu di antaranya adalah serangga. Tujuan penelitian ini adalah untuk mengetahui keanekaragaman serangga pada pertanaman jagung di lahan tadah hujan.

\section{BAHAN DAN METODE}

Pengamatan populasi serangga dilaksanakan dalam periode 1 - 20 Oktober 2019 saat tanaman jagung berumur 78 sampai 96 hari setelah tanam (hst). Pada periode waktu tersebut, pertanaman berada dalam keadaan musim kemarau sehingga ketersediaan air sangat terbatas dan di siang hari temperatur udara dan evaporasi tinggi, kelembaban rendah, serta intensitas cahaya matahari tinggi. Kegiatan bertempat di kebun percobaan Jakenan, di Balai Penelitian Lingkungan Pertanian (Balingtan) Jakenan, Pati, Jawa Tengah. Kegiatan dilakukan di lahan dengan ukuran $5000 \mathrm{~m}^{2}$ menggunakan metode survey. Adapun metode pengumpulan serangganya antara lain dengan menggunakan perangkap cahaya (light trap), perangkap jebakan (pit fall) dan jala ayun (swing net).

\section{Pengumpulan serangga dengan perangkap cahaya (light trap)}

Pengumpulan serangga dengan perangkap cahaya dimaksudkan untuk menangkap serangga yang aktif di malam hari (nocturnal) dan tertarik dengan cahaya. Adapun perangkap cahaya yang terpasang adalah 4 buah dan berada di pematang tengah-tengah lahan tanaman jagung. Perangkap cahaya yang digunakan adalah lampu LED yang dipasang pada kayu berukuran tinggi sekitar $70 \mathrm{~cm}$ yang diberi atap pelindung kemudian di bawah lampu dipasang baskom berukuran 5 liter yang berisi air 1 liter dan diberi $1 \mathrm{~g}$ detergen. Fungsi detergen adalah untuk menimbulkan tegangan permukaan pada air sehingga serangga yang masuk ke dalam air tidak dapat terbang atau keluar lagi. Pengamatan dilakukan hari Senin, Rabu dan Jumat, kemudian serangga yang tertangkap diidentifikasi jenisnya dan dihitung populasinya serta didokumentasikan.

\section{Pengumpulan serangga dengan perangkap jebakan (pitfall)}

Pitfall dibuat menggunakan toples plastik bervolume 1 liter kemudian pada lubang toples 
dipasang corong plastik dengan diameter sebesar lubang toples tersebut dan direkatkan dengan lakban. Selanjutnya, masukkan air sekitar $100 \mathrm{ml}$ ke dalam toples dimana air ini berfungsi agar serangga terperangkap. Toples dipasang pada guludan di tengah-tengah pertanaman dengan cara dibenamkan atau dimasukkan kedalam lubang yang telah terlebih dahulu dibuat menggunakan cangkul. Permukaan toples harus sejajar dengan permukaan tanah agar serangga yang merayap di atas tanah dapat masuk ke dalam lubang corong yang telah terpasang.

Selanjutnya, toples diberi atap agar terhindar dari hujan atau panas dengan jumlah perangkap jebakan yang dipasang adalah 4 buah. Pengamatan dilakukan setiap hari Selasa dan Kamis, kemudian dalam pengamatan tersebut serangga diidentifikasi jenisnya dan dihitung populasinya serta didokumentasikan.

Pengumpulan serangga dengan jala ayun (swing net) Jala ayun dibuat dengan menggunakan jaring yang dipasang pada besi melingkar berdiameter $50 \mathrm{~cm}$ dengan panjang gagang $100 \mathrm{~cm}$. Cara penggunaannya adalah dengan melakukan ayunan tunggal di tengah-tengah tanaman jagung yang kemudian serangga yang tertangkap dimasukkan ke dalam kantong plastik. Penjaringan dilakukan pada 4 petak yang berbeda dengan masing-masing petak dilakukan 30 ayunan. Pengamatan dilakukan setiap hari Senin sampai Jumat, kemudian dalam penjaringan tersebut serangga diidentifikasi jenisnya dan dihitung populasinya serta didokumentasikan.

\section{Analisis Data}

Analisis data untuk mengetahui nilai keanekaragamanya itu dengan menggunakan indeks Shanon wiener dan indeks evenness. Rumus yang digunakan untuk indeks Shanon-Wiener (Beisel et al., 2003).

$$
\mathrm{H}^{`}=-\sum \mathrm{Pi} \ln \mathrm{Pi} \text {, dimana } \mathrm{Pi}=\mathrm{ni} / \mathrm{N}
$$

Keterangan:

H'= Indeks Keragaman Shannon-Wiener

$\mathrm{Pi}=$ Kelimpahan relative masing-masing spesies

$\mathrm{ni}=$ Jumlah individu spesies-i

$\mathrm{N}=$ Total jumlah individu semua spesies

Sedangkan nilai kemerataan populasi serangga dihitung menggunakan indeks kemerataan spesies (evenness) sebagai berikut:

$$
\mathrm{E}=\mathrm{H}^{`} / \ln \mathrm{S}
$$

Keterangan:

$\mathrm{H}^{\prime}$ = Indeks keanekaragaman ShannonWiener

$\mathrm{S}=$ Jumlah spesies

$\mathrm{E}=$ Indeks kemerataan spesies (evenness)

Keragaman suatu populasi serangga dikatakan rendah jika nilai $\mathrm{H}^{`}<1$, sedang jika $1<\mathrm{H}^{`}<3$ dan jika nilai $\mathrm{H}^{`}>1$ maka keragaman serangga dalam populasi tersebut tinggi. Sementara untuk kemerataan memiliki nilai yang berkisar antara 0 dan 1. Jika nilainya 0 menunjukan tingkat kemerataan spesies serangga pada komunitas tersebut sangat tidak merata, sedangkan jika nilainya mendekati 1 maka hampir seluruh spesies yang ada memiliki kelimpahan yang sama.

\section{HASIL DAN PEMBAHASAN}

Iklim merupakan salah satu faktor penting dalam kehidupan makhluk hidup. Populasi serangga sangat dipengaruhi oleh keadaan cuaca. Kekurangan curah hujan atau berlebih akan berakibat tidak baik terhadap perkembangbiakan dan pertumbuhan serangga. Angin berpengaruh terhadap perkembangan serangga hama, terutama dalam proses penyebaran serangga hama tanaman (Kumar \& Mina, 2018).

Berdasarkan data klimatologi (Tabel 1) pada bulan Oktober 2019 diketahui bahwa temperatur minimum malam hari rata-rata sekitar $21,39^{\circ} \mathrm{C}$, sedangkan temperatur maksimum siang hari rata-rata sekitar $41,6^{\circ} \mathrm{C}$, dengan rata-rata temperatur siang sampai sore sekitar $38,18^{\circ} \mathrm{C}$. Kelembaban udara berkisar antara 38,68-96,19\% dengan curah hujan 0 $\mathrm{mm}$ dan rata-rata kecepatan angin sekitar 1,65 $\mathrm{m} /$ detik. Suhu rata-rata di minggu pertama sekitar $3^{\circ} \mathrm{C}$ kemudian meningkat di minggu kedua mencapai $38^{\circ} \mathrm{C}$. Setiap serangga dapat hidup pada kisaran temperatur tertentu, Adapun temperatur optimal bagi kebanyakan serangga adalah $26^{\circ} \mathrm{C}$. Hibernasi umumnya dimulai pada suhu $15^{\circ} \mathrm{C}$, dan aestivasi pada suhu $38^{\circ} \mathrm{C}-45^{\circ} \mathrm{C}$. Pada kondisi temperature yang relatif tinggi, masa perkembangan telur, larva dan pupa dari serangga menjadi lebih pendek (Jaworski \& Hilszanski, 2013). Akan tetapi hal ini tergantung pada jenis serangga itu sendiri, setiap jenis serangga memerlukan kondisi lingkungan yang berbeda bagi pertumbuhan optimumnya.

Pada temperatur optimum, kemampuan hama untuk berkembangbiak besar, dan kematian (mortalitas) sedikit (Rondo, et al, 2016). Kelembapan besar pengaruhnya terhadap kehidupan hama. Bila 
kelembapan sesuai dengan kebutuhan hidup Norhisham et al. (2013) melaporkan bahwa serangga, serangga tersebut cenderung tahan kelembapan dapat mempengaruhi perkembangan, terhadap temperatur ekstrim. Hasil penelitian Khaliq et al. (2014) dan Taradipha dkk. (2018) menyebutkan bahwa air merupakan kebutuhan primer bagi setiap makhluk hidup dan thrips akan berkembangbiak lama hidup dan kemampuan oviposisi serangga. Pada kelembapan rendah, perkembangan serangga seringkali cacat, telur tidak dapat menetas dan lapisan dengan normal pada kelembaban di atas $70 \%$. kutikula serangga menjadi lunak.

Tabel 1. Data klimatologi bulan Oktober 2019

\begin{tabular}{|c|c|c|c|c|c|c|c|}
\hline \multirow{2}{*}{$\mathrm{Tgl}$} & \multicolumn{3}{|c|}{ Suhu Udara $\left({ }^{\circ} \mathrm{C}\right)$} & \multicolumn{2}{|c|}{ Kelembaban (\%) } & \multirow{2}{*}{$\frac{\text { Curah Hujan }}{(\mathrm{mm})}$} & \multirow{2}{*}{$\frac{\text { Kec. angin }}{\text { (m/detik) }}$} \\
\hline & Maks. & Min. & Rerata Siang & Max & Min & & \\
\hline 1 & 41 & 20 & 37,2 & 100 & 40 & 0 & 1,73 \\
\hline 2 & 41 & 21 & 37,7 & 100 & 40 & 0 & 1,71 \\
\hline 3 & 41 & 21 & 37,7 & 100 & 40 & 0 & 1,77 \\
\hline 4 & 41 & 21 & 37,7 & 100 & 40 & 0 & 1,60 \\
\hline 5 & 41 & 21 & 37,8 & 100 & 38 & 0 & 1,97 \\
\hline 6 & 42 & 21 & 38,2 & 100 & 37 & 0 & 1,89 \\
\hline 7 & 42 & 22 & 38,0 & 96 & 40 & 0 & 1,89 \\
\hline 8 & 41 & 22 & 38,2 & 97 & 40 & 0 & 1,63 \\
\hline 9 & 41 & 21 & 37,7 & 100 & 39 & 0 & 1,62 \\
\hline 10 & 41 & 22 & 38,0 & 97 & 40 & 0 & 1,68 \\
\hline 11 & 41 & 21 & 38,3 & 100 & 38 & 0 & 1,59 \\
\hline 12 & 42 & 21 & 38,3 & 97 & 37 & 0 & 1,53 \\
\hline 13 & 42 & 22 & 38,7 & 100 & 38 & 0 & 1,56 \\
\hline 14 & 42 & 21 & 38,0 & 100 & 38 & 0 & 1,64 \\
\hline 15 & 42 & 21 & 38,7 & 95 & 38 & 0 & 1,62 \\
\hline 16 & 42 & 22 & 38,5 & 92 & 40 & 0 & 1,67 \\
\hline 17 & 41,5 & 21 & 37,7 & 97 & 41 & 0 & 1,65 \\
\hline 18 & 41 & 21 & 37,8 & 94 & 38 & 0 & 1,55 \\
\hline 19 & 41 & 22 & 39,0 & 88 & 37 & 0 & 1,66 \\
\hline 20 & 42 & 22 & 38,5 & 93 & 38 & 0 & 1,56 \\
\hline 21 & 42 & 21 & 37,8 & 100 & 40 & 0 & 1,65 \\
\hline 22 & 42 & 22 & 38,7 & 94 & 38 & 0 & 1,76 \\
\hline 23 & 42 & 21 & 38,7 & 96 & 35 & 0 & 1,83 \\
\hline 24 & 43 & 21 & 38,3 & 94 & 38 & 0 & 1,51 \\
\hline 25 & 42 & 21 & 37,7 & 96 & 40 & 0 & 1,77 \\
\hline 26 & 41 & 22 & 38,0 & 92 & 43 & 0 & 1,45 \\
\hline 27 & 41 & 22 & 38,8 & 89 & 40 & 0 & 1,34 \\
\hline 28 & 42 & 22 & 38,5 & 95 & 37 & 0 & 1,64 \\
\hline 29 & 42 & 22 & 38,7 & 94 & 38 & 0 & 1,67 \\
\hline 30 & 42 & 21 & 38,3 & 95 & 37 & 0 & 1,59 \\
\hline 31 & 42 & 22 & 38,7 & 91 & 36 & 0 & 1,54 \\
\hline Rata-rata & 41,60 & 21,39 & 38,18 & 96,19 & 38,68 & 0,00 & 1,65 \\
\hline
\end{tabular}

Sumber: Data iklim bulan Oktober 2019-Stasiun Klimatologi Kebun Percobaan Jakenan. 


\section{Hasil pengamatan perangkap cahaya (Light Trap)}

Dari hasil identifikasi terhadap serangga yang diperoleh dari light trap, ditemukan bahwa populasi serangga pada pertanaman jagung yang tinggi yaitu serangga yang termasuk pada ordo Lepidoptera, Coleoptera, Hemiptera, sedangkan Hymenoptera, Diptera, Dermaptera, dan Neuropteran populasinya cenderung rendah. Akan tetapi, seiring dengan pertambahan umur tanaman jagung dan peningkatan suhu udara populasi serangga cenderung menurun, dimana suhu udara awalnya sekitar $37,8{ }^{\circ} \mathrm{C}$ dan meningkat mencapai $38,1^{\circ} \mathrm{C}$.
Ordo Lepidoptera dan Hemiptera yang terperangkap umumnya merupakan golongan serangga yang berperan sebagai hama, sedangkan serangga dari ordo Coleoptera, Hymenoptera, Dermaptera, dan Neuroptera yang terperangkap umumnya merupakan sebagai musuh alami. Bila melihat dari populasi yang ada maka dapat disimpulkan bahwa populasi serangga yang bertindak sebagai hama hampir sebanding dengan populasi serangga musuh alami, sehingga kondisi seperti ini mengakibatkan adanya keseimbangan dalam ekosistem yang memungkinkan terjadi serangan hama yang relatif dapat dikendalikan.

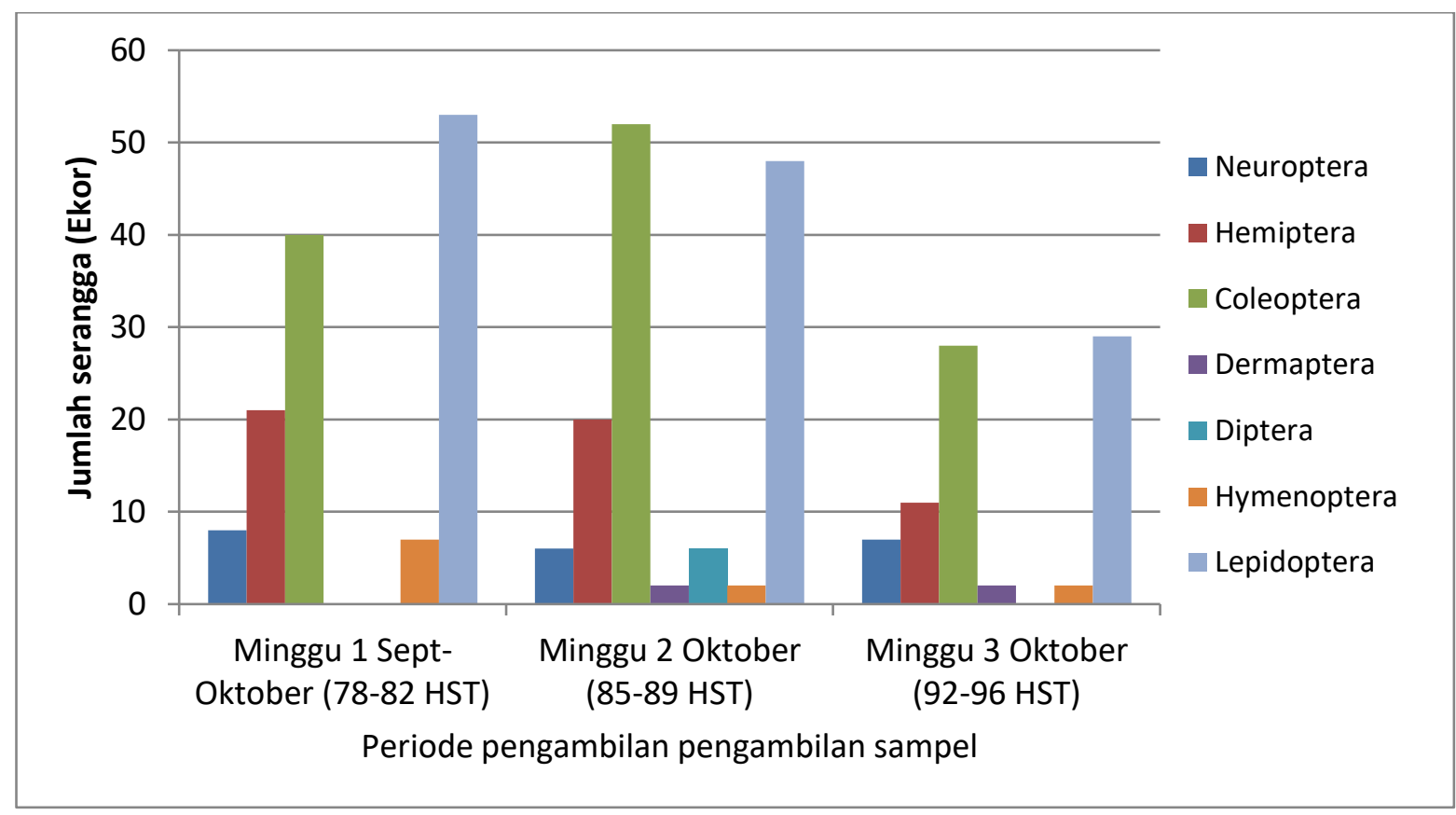

Gambar 1. Tingkat populasi dan keragaman serangga pada pengamatan menggunakan light trap.

Adanya keseimbangan ekosistem ini disebabkan oleh penggunaan pestisida kimia yang terkendali selama pengelolaan lahan di tempat penelitian dan sering digunakannya pestisida nabati yang tidak berbahaya bagi musuh alami. Organisme yang teramati dengan light trap merupakan serangga nocturnal yang sangat tertarik kepada cahaya. Species yang dominan teramati di light trap yaitu dari ordo Lepidoptera antara lain: Scirpophaga incertulas, Helicoperva armigera, Ostrinia purnacalis, dari ordo Coleoptera antara lain Dystiscus sp, Paederus fuscipes, Coccinella, Ophionea nigrofasciata, dari ordo hemiptera: Nephotettix virescens, Nezara viridula, Leptocorisa acuta.

\section{Hasil pengamatan perangkap jebakan (PitFall)}

Hasil identifikasi terhadap serangga yang diperoleh pada perangkap pitfall menunjukkan bahwa umumnya serangga yang terperangkap adalah dari ordo Hymenoptera seperti semut dan lebah. Serangga dari ordo Hymenoptera ini merupakan spesies yang menjadi musuh alami kebanyakan serangga dan juga sebagai serangga penyerbuk. Hasil ini dapat kita simpulkan bahwa musuh alami banyak yang aktif di daerah dasar tanaman atau dekat tanah. Hal ini dapat diduga memang salah satunya akibat cuaca yang panas sehingga memaksa mereka untuk berada di daerah yang lebih lembap dan rimbun. 


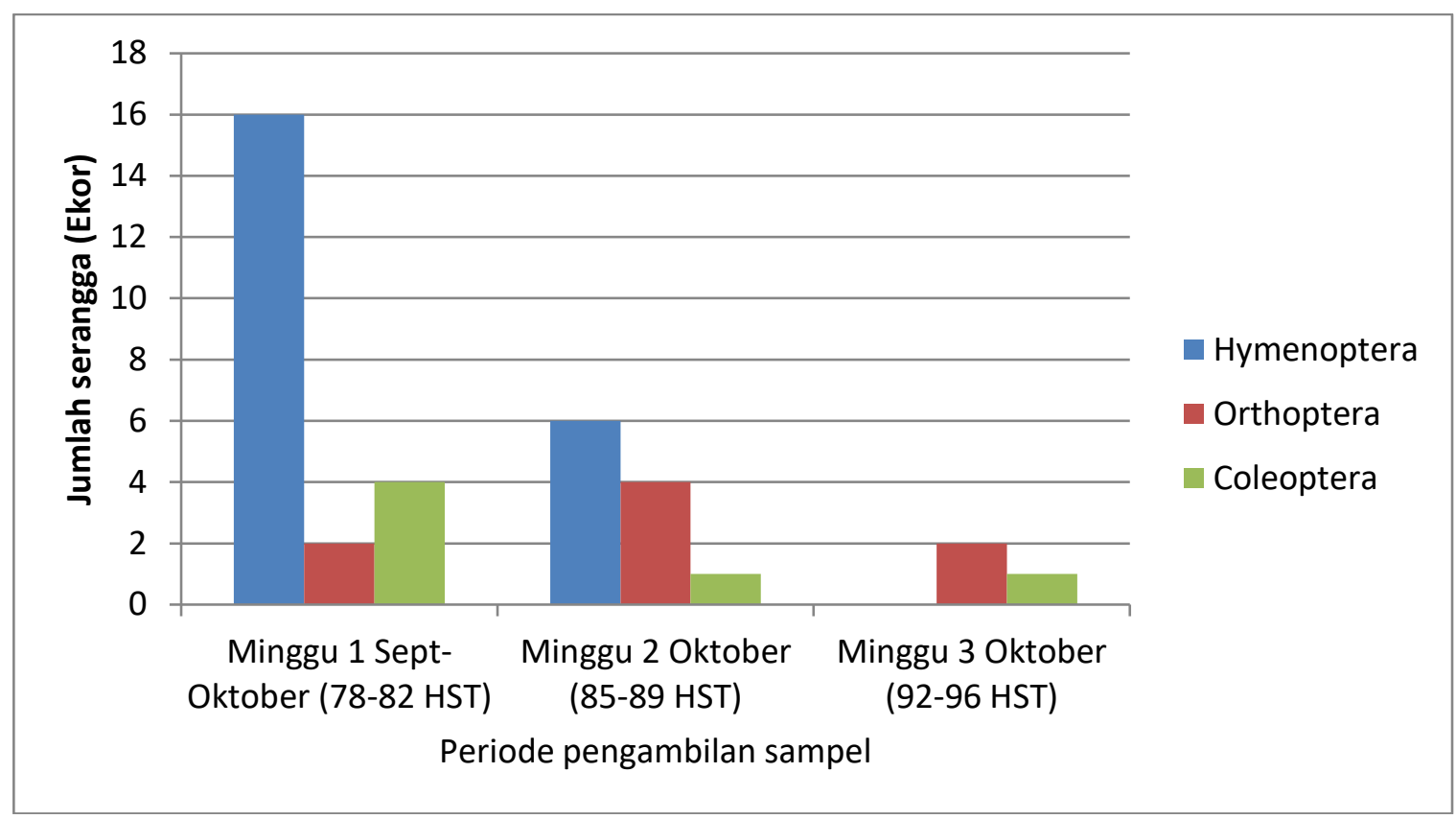

Gambar 2. Tingkat populasi dan keragaman serangga pada pengamatan menggunakan pitfall.

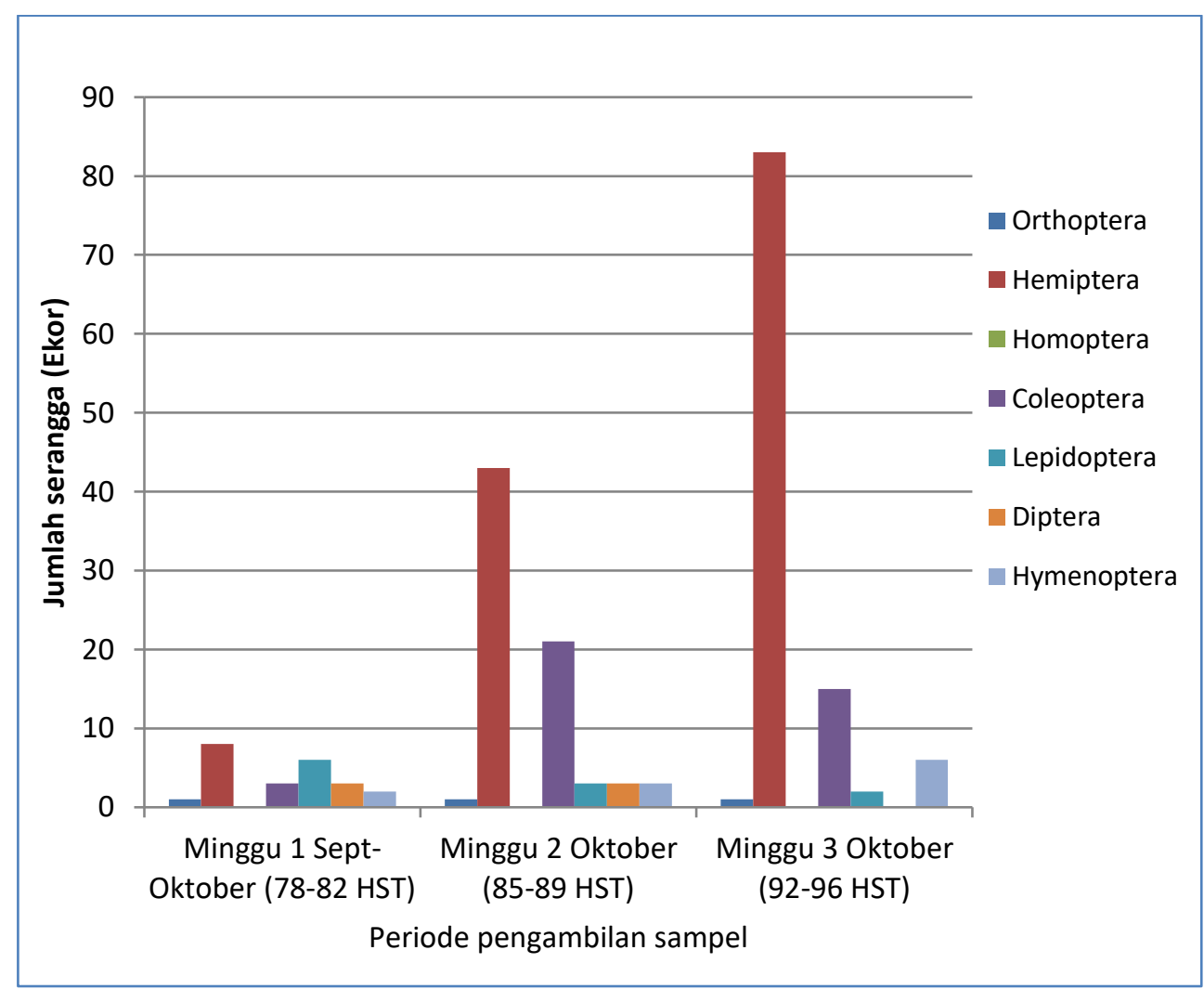

Gambar 3. Tingkat populasi dan keragaman serangga pada pengamatan menggunakan swing net.

Populasi serangga tersebut cenderung menurun seiring semakin mendekati masa panen jagung dan seiring peningkatan temperatur udara. Species dominan teramati di pitfall yaitu Gryllus mitratus, C. consobrinus, Cercerisa renaria.

\section{Hasil pengamatan jala ayun ( $S_{w i n g} N e t$ )}

Populasi serangga yang tinggi yang diperoleh melalui jala ayun adalah serangga dari ordo Hemiptera atau dari golongan kepik kemudian disusul serangga dari ordo Coleoptera. Pada minggu 
pertama bulan Oktober populasi serangga dari tiap ordo cenderung hampir sama, akan tetapi pada minggu selanjutnya yang banyak tertangkap adalah dari golongan kepik. Hal ini berarti pada minggu kedua, ketiga dan selanjutnya populasi kepik sangat tinggi. Kondisi tersebut diduga berhubungan dengan kondisi cuaca pada bulan tersebut yang semakin tinggi temperaturnya. Golongan kepik dapat beradaptasi, baik terhadap cuaca, makanan, maupun ketersediaan air yang terbatas. Kepik merupakan hama dengan tipe mulut penusuk penghisap, jadi biasanya hama ini menghisap cairan tanaman, sehingga tanaman menjadi kering. Species yang dominan teramati di jala ayun yaitu Leptocorisa acuta, Paederus fuscipes, Nephotettix virescens, Oxyopes lineatipes, Nezara viridula.

\section{Total populasi berbagai jenis serangga}

Total populasi serangga yang berada di sekitar pertanaman jagung tadah hujan dapat dilihat pada Gambar 4. Terlihat bahwa jenis serangga yang dominan adalah dari ordo Hemiptera, Coleoptera, dan Lepidoptera. Dari ordo Hemiptera, $N$. viridula dan Nephotettix virescens adalah serangga yang paling banyak populasinya pada saat pengamatan. Kedua spesies serangga ini merupakan bukan merupakan hama utama tanaman jagung akan tetapi dapat bertahan di ekosistem tanaman jagung dengan memanfaatkan berbagai gulma sebagai bahan makanan. Sebelum dan setelah tanaman jagung di lahan tadah hujan ini biasanya ditanami padi, sehingga memang untuk Nephotettix virescens khususnya dapat menjadi ancaman timbulnya populasi yang besar dan menyerang tanaman padi berikutnya. Dari ordo coleoptera, Paederus fuscipes dan Ophionea nigrofasciata adalah serangga yang dominan, dimana kedua species ini merupakan musuh alami dari Nephotettix virescens. Dari ordo Lepidoptera, Helicoperva armigera dan Ostrinia purnacalis adalah spesies serangga yang dominan, dimana keduanya merupakan hama utama tanaman jagung.

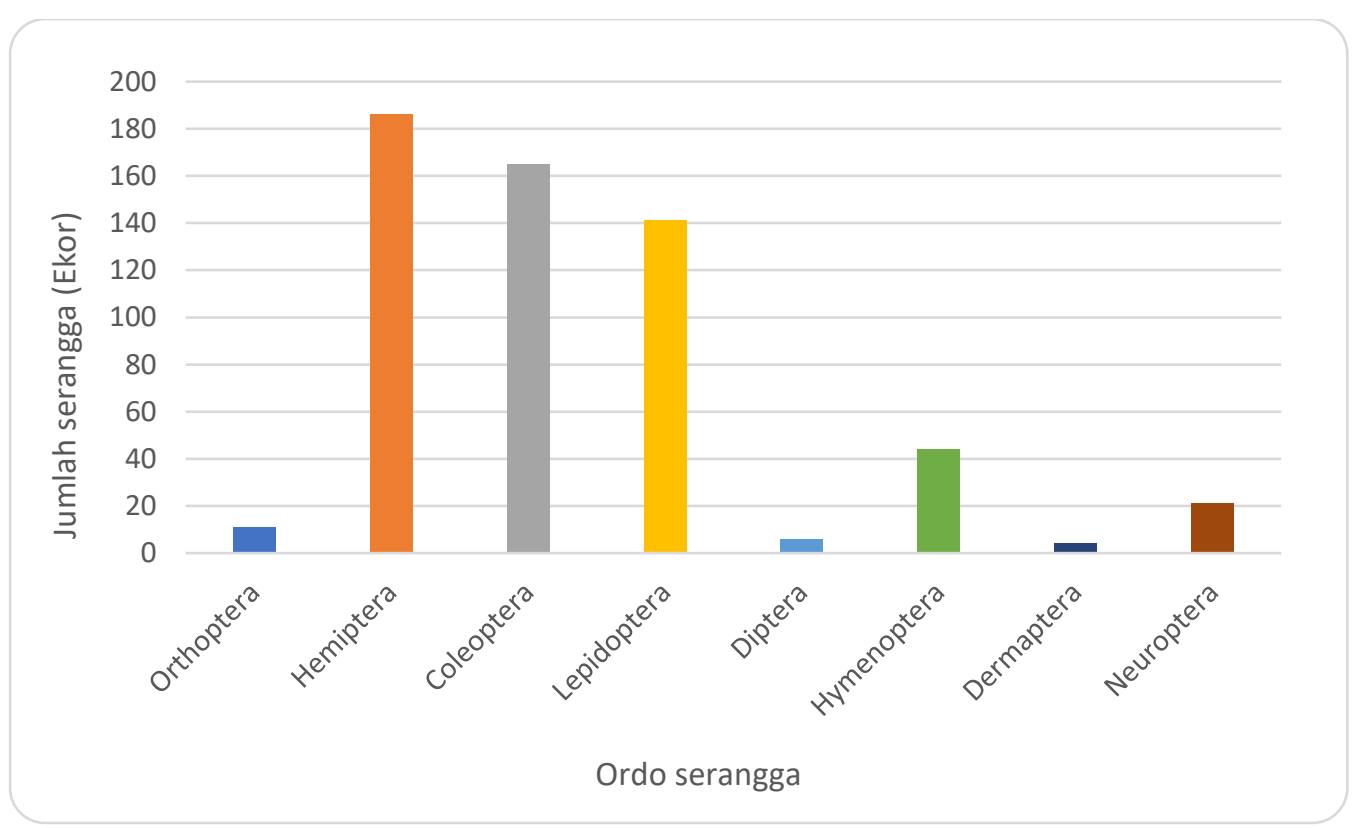

Gambar 4. Tingkat total populasi berbagai jenis serangga.

Tabel 2. Indeks keragaman dan kemerataan jenis serangga.

\begin{tabular}{llcc}
\hline No & Waktu Observasi & Indeks Keragaman $\left(\mathrm{H}^{`}\right)$ & Indeks Kemerataan $(\mathrm{E})$ \\
\hline 1 & Minggu 1 Sept-Oktober (78-82 HST) & 1,67 & 0,80 \\
\hline 2 & Minggu 2 Oktober (85-89 HST) & 1,58 & 0,72 \\
\hline 3 & Minggu 3 Oktober (92-96 HST) & 1,42 & 0,68 \\
\hline
\end{tabular}




\section{Keragaman dan kemerataan jenis serangga}

Dari Tabel 2 terlihat bahwa indeks keragaman $\left(H^{\prime}\right)$ jenis serangga pada tiap jenis perangkap berada dikisaran $1<\mathrm{H}^{`}<3$. Hal ini berarti serangga yang tertangkap memiliki keragaman yang sedang atau boleh dikatakan cukup beragam jenisnya. Sementara itu nilai indeks kemerataan (E) populasi jenis serangga apabila nilainya sama dengan 1 berarti sangat merata, jika nilainya semakin mendekati 0 berarti ada dominasi. Pada setiap waktu pengamatan indeks keragaman bernilai sedang dan indeks kemerataan bernilai hampir merata.

\section{SIMPULAN}

Jenis serangga yang dominan pada pengamatan perangkap lampu adalah serangga dari ordo Lepidoptera yaitu berupa ngengat, sedangkan pada pengamatan menggunakan perangkap jebakan yang dominan adalah serangga dari golongan Hymenoptera atau berupa semut dan lebah. Sementara itu pada pengamatan menggunakan jala ayun serangga yang dominan adalah dari ordo Hemiptera atau golongan kepik. Akan tetapi secara umum dari ketiga metode penangkapan tersebut, ordo Hemiptera adalah ordo yang mendominasi pada pertanaman jagung tadah hujan. Pada setiap waktu pengamatan indeks keragaman bernilai sedang dan indeks kemerataan bernilai hampir merata.

\section{UCAPAN TERIMA KASIH}

Penelitian ini merupakan kegiatan mandiri dan mengikuti sebagian aktivitas di Kebun Percobaan Jakenan. Oleh karena itu kami ucapkan terimakasih kepada Kepala Kebun Bapak Edi Supraptomo S.ST atas ijin dan kerjasamasanya serta saudara Apririo Dwi Sujatmiko Nugroho yang telah membantu pengamatan penelitian ini.

\section{DAFTAR PUSTAKA}

Ashfaq, S, IA Khan, M Saeed, AUR Saljoqi, F Manzoor, K Sohail, K Habib, and A Sadozai. 2011. Population dynamics of insect pests of cotton and their natural enimies. Sarhad Journal of Agriculture. 27 (2): 201-251.

Beisel, JN, P Usseglio-Polatera, V Bachmann, and JC Moreteau. 2003. A comparative analysis of evenness index sensitivity. International Review of Hydrobiology. 88: 3 - 15. 10.1002/iroh.200390004.
Jaworski, T, and J Hilszczanski. 2013. The effect of temperature and humidity changes on insects development and their impact on forest ecosystems in the context of expected climare change. Forest Research Paper. 74 (4): 345-355.

Kasryno, F, E Pasandaran, dan AM Fagi. 2002. Dinamika Produksi dan Pembangunan Sistem Komoditi Jagung Indonesia. Ekonomi Jagung Indonesia. Hal 307-341.

Khaliq, A, M Javed, M Sohail, and M Sagheer. 2014. Environmental effects on insects and their population dynamics. Journal of Entomology and Zoology Studies. 2 (2): 1-7.

Kumar, P, and U Mina. 2018. Fundamentals of Ecology and Environment. Pathfinder Publication. New Delhi. India. $240 \mathrm{p}$

Mas'ud, S, A Tenrirawe, dan MS Pabbage. 2009. Dinamika populasi hama utama jagung. Prosiding Seminar Nasional Serealia 2009. ISBN :978-979-8940-27-9.

Norhisham, AR, F Abood, M Rita, and KR Hakeem. 2013. Effect of humidity on egg hactability and reproductive biology of the bamboo borer (Dinederus minutus Fabricius). Spingerplus. 2 (9). doi:10.1186/2193-1801-2-9.

Oktavia, V. 2017. Respon Pertumbuhan dan Hasil TanamanJagung Manis (Zea Mays Saccharata Sturt.) Terhadap Pengaruh Dosis Dan Waktu Pemupukan Pupuk Cair Bio-Slurry. [Skripsi] Fakultas Pertanian Universitas Lampung Bandar, Lampung.

Salelua, SA, dan S Maryam. 2018. Potensi dan prospek pengembangan produksi jagung (Zea mays L.) di Kota Samarinda. Jurnal Agribisnis Komunikasi Pertanian. 1 (1): 47-53.

Shahabuddin, P Hidayat, WA Noerdjito, dan S Manuwoto. 2005. Penelitian biodiversitas serangga di Indonesia: Kumbang tinja (Coleoptera: Scarabaeidae) dan peran ekosistemnya. BIODIVERSITAS. 6 (2): 141146 Doi: 10.13057/Biodiv/D060215.

Rondo, SF, IM Sudarma, dan G Wijana. 2016. Dinamika populasi hama dan penyakit utama tanaman jagung manis (Zea mays saccharata Sturt) pada lahan basah dengan sistem budidaya konvensional serta pengaruhnya terhadap hasil di Denpasar-Bali. Agrotrop. 6 (2): $128-136$.

Taradipha, MRR, SB Rushayati, dan NF Haneda. 2018. Karakteristik lingkungan terhadap komunitas serangga. Journal of Natural Resources and 
Environmental Management. 9(2): 394-404. http://dx.doi.org/10.29244/jpsl.9.2.394-404.

Yamamura, K, M Yokozawa, M Nishimori, Y Ueda, and $\mathrm{T}$ Yokosuka. 2006. How to analyze long- term insect population dynamics under climate change: 50-year data of three insect pests in paddy fields. Population Ecology. 48: 31-48 DOI 10.1007/s10144-005-0239-7. 